\title{
PHYSICAL MODEL FOR SMALL SCALE SANDWAVES MIGRATION IN NORTH GULF OF SOUTH CHINA SEA
}

\author{
Mian Lin* \\ Department of Ocean \\ Environment and Engineering
}

\author{
Yong Li \\ Department of Ocean \\ Environment and Engineering
}

\author{
Wenbin Jiang \\ Department of Ocean \\ Environment and Engineering
}

\author{
Laboratory of Environmental Mechanics, \\ Institute of Mechanics, Chinese Academy Sciences, Beijing 100190, China
}

\begin{abstract}
The aim of this paper is to investigate the mechanism of small scale sand-wave migration. According to the environmental characteristic of the north gulf of South China Sea, a quasi-3D mechanics model has been built for simulating the small scale sand wave migration. The calculation results are shown to be consistent with the observed data in the trough of sand ridge. Considering the effect of environmental actions and sand wave features, we develop an effective formula to predict sand-wave migration. It is indicated that the physical models should be used to predict the migration of the small scale sandwave, which is rarely dominated by wave activity.
\end{abstract}

\section{INTRODUCTION}

Sand-waves, covering the sandy bed in shallow seas, are known to be more dynamic than the larger sand ridges and sandbanks, so they endanger the safety of many offshore structures in the shelf seas, such as harbors, petroleum pipelines and communication cables [1]. Thus to investigate the sand-wave migrating is an important project [2].

In general, the heights of sand-waves are typically several metres, their wavelength may cover from a few tens metres to kilometers and their patterns and spatial positions vary with time due to the action of ocean flows [3].

For long time, the sand-wave dynamics has been described as a function of tidal current. Hulscher[4] developed a model allowing for vertical circulation and described the initial evolution of sand-wave based on a horizontally averaged symmetrical tidal motion. The model showed that the net convergence of sand can occur at the top of the sand-wave over an entire tidal cycle ([5], [6]). And the sand-wave migration was not discussed. Németh [7] extended the model by including an asymmetric basic flow, inducing sand wave migration. It should be noticed that the model is for the sand-wave with long wavelength, the same order of tidal wavelength, called large scale sand-wave.

But in some sea area sand-waves with short wavelength are often observed even if the wave heights still reach a few metres [8]. As the sand wave length is below one hundred meter, which is called small scale sand-wave. For the knowledge of the interaction of flow field and sediment transport, the migration mechanism for the small scale sand wave must differ from the large scale sand-wave. In this paper we will concern the problem.

Considering the area of North Gulf of South China Sea, a quasithree dimensional physical model for small scale sand wave is proposed. By comparing with the observational data, the model is verified. And finally the migration regularity in southwest of Hainan island is discussed and any effective formula is proposed.

\section{PHYSICAL MODEL}

\subsection{Study Area}

The region of southwest of Hainan Island located at North Gulf of South China Sea is a typically shallow sea, and the average water depth is about $42 \mathrm{~m}$. Based on the statistic of hydrological data in the gulf, the principal tidal component is of diurnal tide due to the amplitude of solar tidal wave larger than that of semidiurnal tidal wave. The wavelengths of the water waves

\footnotetext{
* Professor and author of correspondence
} 
often cover $15 \mathrm{~m}-39 \mathrm{~m}$, the wave heights are less or equal to $1.2 \mathrm{~m}$, and the periods range typically $3.1 \mathrm{~s}-5.0 \mathrm{~s}$.

Besides tidal currents and water waves, the region is often characterized by the monsoon generated by the Asia monsoon and Australia monsoon. According to meteorological data, the wind orientation is NE from October to next March every year, with an average velocity of $5.83 \mathrm{~m} / \mathrm{s}$. The orientation is S-SSW from May to August, with an average velocity of $7.19 \mathrm{~m} / \mathrm{s}$. The wind orientation reverses during April and September every year.

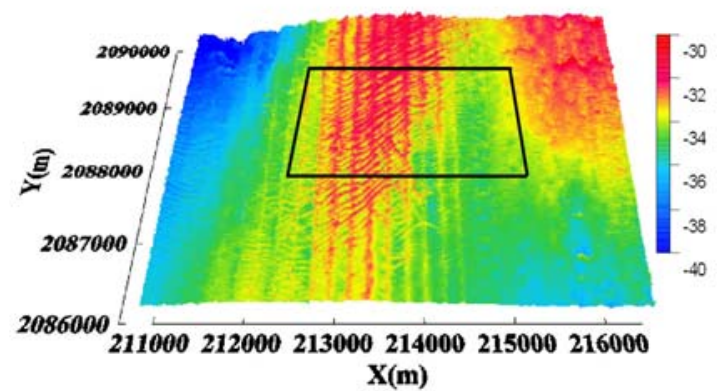

Figure 1a. Bathymetry measurements made in North Gulf of South China.

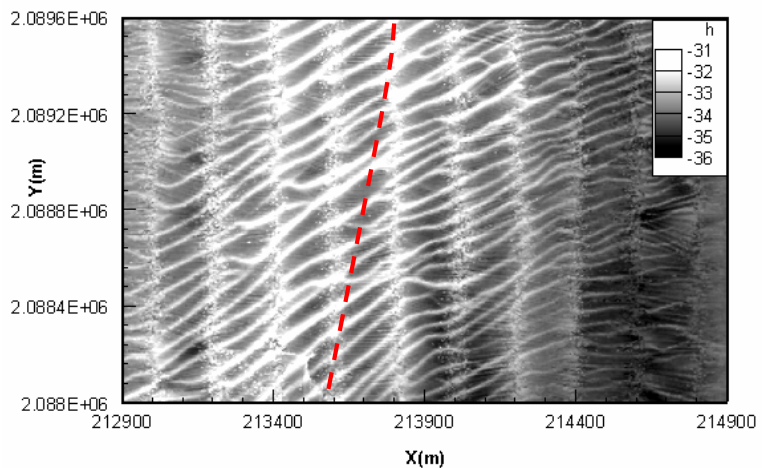

Figure 1b. Multibeam image of July 2004 in the study area. The dashed line depicts the position of sand ridge.

From June 2004 to October 2005, the scientists of Chinese Academy of Sciences have surveyed the submarine microgeomorphic features using multi-beam system in the region from $\left(1850.75^{\prime} \mathrm{N}, 10815.45^{\prime} \mathrm{E}\right)$ to $\left(1852.966^{\prime} \mathrm{N}, 108\right.$ $18.49^{\prime}$ E) (Figure 1). In this study, we intercept the region from $\left(18^{\circ} 51.84^{\prime} \mathrm{N}, 108^{\circ} 16.23^{\prime} \mathrm{E}\right)$ to $\left(18^{\circ} 52.73^{\prime} \mathrm{N}, 108^{\circ} 17.81^{\prime} \mathrm{E}\right)$, which cover a number of sand-waves more than 30, with an average wavelength $33 \mathrm{~m}$ and a small amplitude less or equal to $2 \mathrm{~m}$, as indicated by the black square in Figure 1a. The multibeam images reveal a sand ridge with superimposed compound sand-wave (Figure 1b). The wavelengths of these sand-waves, belonging to shallow water region, are much smaller than the tidal wavelength and they should be small scale sand waves.

\subsection{Flow Field Model}

For the small scale sand-wave in the study area of this paper, the fluid motion is consisted of two layers: tidal current layer and wind driven current layer. Firstly, we use the depth-averaged shallow water equations to describe the tidal flow:

$$
\left.\begin{array}{l}
\frac{\partial \xi}{\partial t}+\frac{\partial}{\partial x}(H u)+\frac{\partial}{\partial y}(H v)=0 \\
\frac{\partial u}{\partial t}+u \frac{\partial u}{\partial x}+v \frac{\partial u}{\partial y}=f v-g \frac{\partial \xi}{\partial x}+\varepsilon\left(\frac{\partial^{2} u}{\partial x^{2}}+\frac{\partial^{2} u}{\partial y^{2}}\right)-\frac{1}{\rho H} \tau_{x}^{b} \\
\frac{\partial v}{\partial t}+u \frac{\partial v}{\partial x}+v \frac{\partial v}{\partial y}=-f u-g \frac{\partial \xi}{\partial y}+\varepsilon\left(\frac{\partial^{2} v}{\partial x^{2}}+\frac{\partial^{2} v}{\partial y^{2}}\right)-\frac{1}{\rho H} \tau_{y}^{b}
\end{array}\right\}
$$

Here $\xi$ is the free surface elevation; $H$ is the undisturbed water depth; $u$ and $v$ are the velocity components in the longitude (x) and latitude (y); $g$ is the acceleration of gravity; $\varepsilon$ is the eddy viscosity coefficient, $f$ is the Coriolis forcing; $\tau_{x}^{b}$ and $\tau_{y}^{b}$ are the shear stresses at the sea bottom in the $x$ and $y$ directions respectively, and written as:

$$
\tau_{(x, y)}^{b}=(u, v) C_{f} \sqrt{u^{2}+v^{2}} / H
$$

where $C_{f}=g(2.6-H / 200)^{2} / 10^{6} H^{1 / 3}$, as $H<200 m$.

In the bottom boundary layer, we consider the effect of seasonal wind near the sea bottom. Assuming a steady-state flow driven by the wind, the velocity field in vertical at the two-dimension continental margin is as follows [9]:

$$
\left.\begin{array}{l}
u_{b}(z)=\left(\frac{U_{*_{c}}}{\kappa} \ln \left(\frac{z}{k_{b}}\right)+8.5 U_{*_{c}}\right) \cos \gamma \\
v_{b}(z)=\left(\frac{U_{*_{c}}}{\kappa} \ln \left(\frac{z}{k_{b}}\right)+8.5 U_{*_{c}}\right) \sin \gamma
\end{array}\right\}
$$

A partial slip condition compensate for the constant eddy viscosity, which overestimates the eddy viscosity near the bed. Here $U_{*_{c}}=\sqrt{\tau_{c} / \rho_{f}}$ is the shear velocity at the top of the bottom boundary layer, $\kappa$ is von Karman's coefficient, $k_{b}$ is the physical bottom roughness, $\tau_{c}=c_{d} R|R|$ is the bottom current shear stress, $R=\sqrt{Q^{2} c_{d s} \rho_{a} \cos \alpha / c_{d} \rho \cos \gamma}$ is the bottom current velocity, relying on the wind speed $Q$, friction drag coefficient at the water surface and at the bed $c_{d s}, c_{d}$, air density $\rho_{a}$, wind and surface stress orientation $\alpha$ and bottom current orientation relative to the coast $\gamma$ :

$$
\begin{array}{r}
\left(\sqrt{f \varepsilon(\rho \cos \alpha \cos \gamma) /\left(\rho_{a} c_{d} c_{d s}\right)}\right) \sin \gamma(\cosh H \sqrt{2 f / \varepsilon}-\cos H \sqrt{2 f / \varepsilon})= \\
2 Q \cos \gamma[\sin (\alpha-\pi / 4) \sinh H \sqrt{f / 2 \varepsilon} \cos H \sqrt{f / 2 \varepsilon}- \\
-\cos (\alpha-\pi / 4) \cosh H \sqrt{f / 2 \varepsilon} \sin H \sqrt{f / 2 \varepsilon}] \\
-Q \cos \alpha[\sin (\alpha-\pi / 4) \sinh H \sqrt{2 f / \varepsilon} \\
-\cos (\gamma-\pi / 4) \sin H \sqrt{2 f / \varepsilon}]
\end{array}
$$

Thus, equations (1) and (2) describe a quasi-three dimensional flow field model near the bottom. 


\subsection{Sediment Transport Model}

The flow and the sea bed are coupled through the continuity of sediment. Here two formulations have been considered:

$$
\frac{\partial \eta}{\partial t}+\frac{\partial}{\partial x}\left(q_{x}-\lambda_{m}\left|q_{x}\right| \frac{\partial \eta}{\partial x}\right)+\frac{\partial}{\partial y}\left(q_{y}-\lambda_{m}\left|q_{y}\right| \frac{\partial \eta}{\partial y}\right)=0
$$

where $(\partial \eta / \partial t)$ is the instantaneous rate of change in height of sand-wave; $\lambda_{m}$ denotes sand wave slope; $\vec{q}\left(q_{x}, q_{y}\right)$ is the volumetric sediment transport.

The sediment is transported in two ways: as bed load transport and as suspended load transport. The bed load flux is:

$$
\vec{q}_{\text {bedload }}= \begin{cases}0.8 \sqrt{d}\left(|\bar{u}| / u_{0}\right)^{3}\left(\vec{u}-u_{0}\right)\left(\frac{d}{0.7|H|}\right)^{\frac{1}{10}} & |\bar{u}|>u_{0} \\ 0 & |\bar{u}| \leq u_{0}\end{cases}
$$

where $u_{0}=3.6 d^{1 / 3}(0.7|H|)^{1 / 10}, \vec{u}(u, v)$ is the velocity near the seabed, $d$ is the mean diameter of the sediment. The suspended flux is:

$$
\vec{q}_{\text {susp }}=\int_{z=z_{0}}^{z=Z_{\text {ref }}} C_{z}[\vec{u}(z)] d z
$$

where $Z_{\text {ref }}$ is the depth of the flow over which the sediment is suspended, and $\vec{u}(z)=\vec{u}\left(u_{b}(z), v_{b}(z)\right)$ is the velocity profile, $\mathrm{C}_{\mathrm{z}}$ is the mean volumetric sediment concentration at height $\mathrm{z}$ above the bed, which satisfies:

$$
\frac{C_{z}}{C_{z_{0}}}=\left(\frac{z}{z_{0}}\right)^{-\left(\gamma_{s} w_{f} / \kappa U_{*}\right)}
$$

Here $w_{f}$ is the grain settling velocity, $\gamma_{s}$ is a constant given by [10], $\kappa$ is von Karman's coefficient, $z_{0}\left(z_{0}=k_{b} / 30\right)$ is a length scale that is proportional to the physical bottom roughness, $z$ is the height above the bed, $C_{z_{0}}=C_{b} \gamma_{0} S /\left(1+\gamma_{0} S\right)$ is the mean reference concentration at $z_{0}$, $U_{*_{c}}$ is the pure current shear velocity, $\gamma_{0}$ is a resuspension coefficient, $S$ is the normalized mean excess boundary shear stress.

Because the sea-bottom, characterized by the variable $\eta$, does not change significantly in the time scale of the tidal constituents, the morphological changes are derived through a new time variable.

In the next section, we will concern fully the influences of the water depth, bottom profile and sediment transport way on sand-wave migration.

\section{RESULTS AND DISCUSSION}

Based on the multibeam bathymetric data of July 2004, the crests positions of the sand-wave after 15 months are simulated and plotted in Figure 2. It is obvious that the deeper the water, the preciser the prediction. The sand-wave velocity in zones with an average water depth $33 \mathrm{~m}$ is $12.5 \mathrm{~m} / \mathrm{yr}$ and with an average water depth $35 \mathrm{~m}$ it is $7.5 \mathrm{~m} / \mathrm{yr}$, compareing to the observed values $12.05 \mathrm{~m} / \mathrm{yr}$ and $7.84 \mathrm{~m} / \mathrm{yr}$, respectively. Above the sand ridge (dash line), the calculation results are not in agreement with the observed data. We think the water depth is a key physical parameter. We will discuss the reason later.

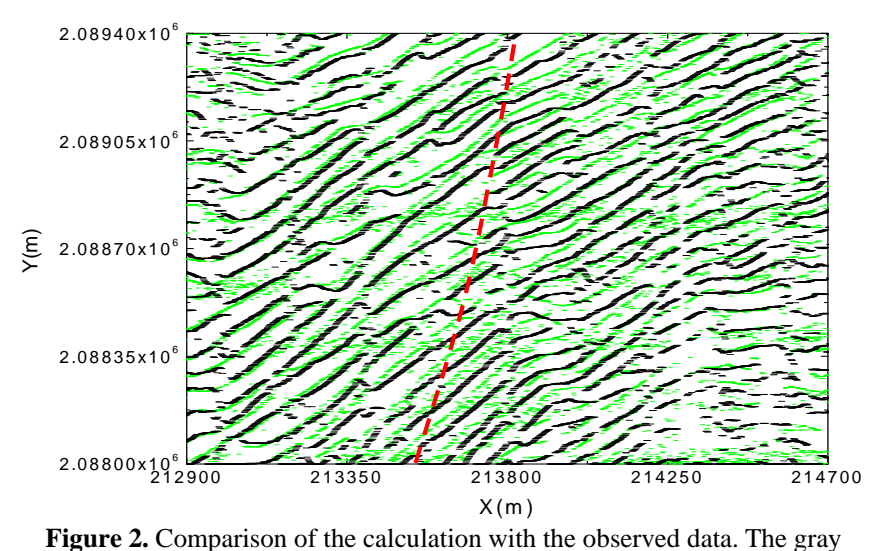
dashes denote the observed data of Oct. 2005, and the black dashes denote the calculation results. The dashed line depicts the position of sand ridge

Now we figure out the sand-wave slope. The solutions are drawn in Figure 3a (in this figure the migration direction is from right to left). The figure shows that the parameter $\lambda_{m}$ expedites sand-wave migration, with an average spacing of $4 \mathrm{~m}$. It is implied that the sand wave slope plays an important role in their movement.

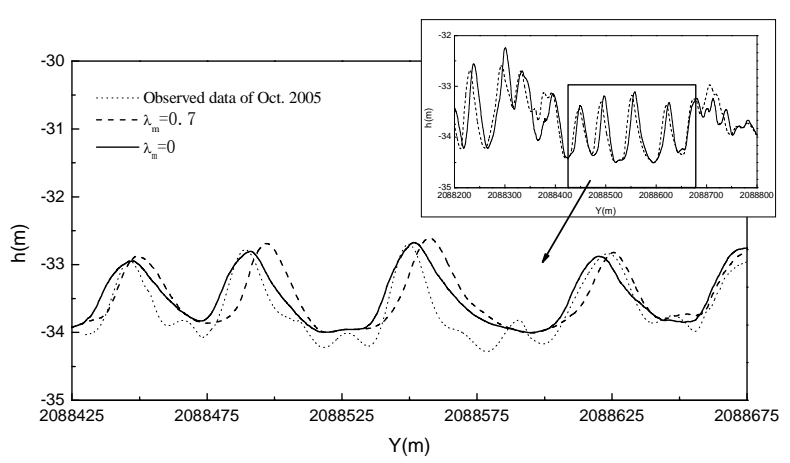

Figure 3a. Sand-wave profile situated parallel to the principal tidal current direction.

Then leading another parameter: symmetry index $\alpha$ $\left(\alpha=\left(L_{1}-L_{2}\right) / L\right.$, here $L=L_{1}+L_{2}, L_{1}=L_{2}$ means the sand-wave absolutely symmetry), we analyze the variation of $\alpha$ with the migration velocity $c$. The study area, not including the sand ridge back region, is divided into six zones according to the average water depth. From the calculation results we can obtain the moving velocity for every sand-wave, as plotted in Figure $3 \mathrm{~b}$. The following relation can be deduced ([11], [12]):

$$
c \propto f\left(\alpha^{2}\right)
$$




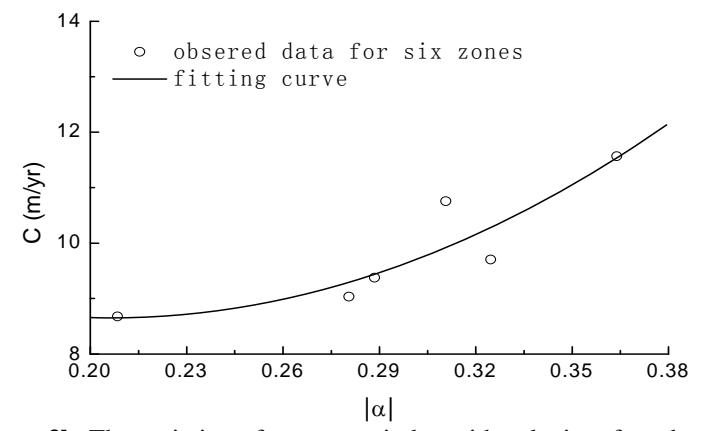

Figure $3 \mathbf{b}$. The variation of symmetry index with velocity of sand-wave migration in the sand ridge trough

We also consider a comparison between the tidal current and the incorporating current of tide and season. Figure 4 shows the results. In this figure, the principal tidal direction is from right to left, with right being N-NW. It is obvious that the migration rate reduces due to the wind-driven current. The discrepancy almost reaches $10 \mathrm{~m}$. The reason is that there are three times of monsoon reversals during the two measurements and every reversal causes the moving orientation to change absolutely. So eventually it seems that the migration rate is slower than that the only tide condition.

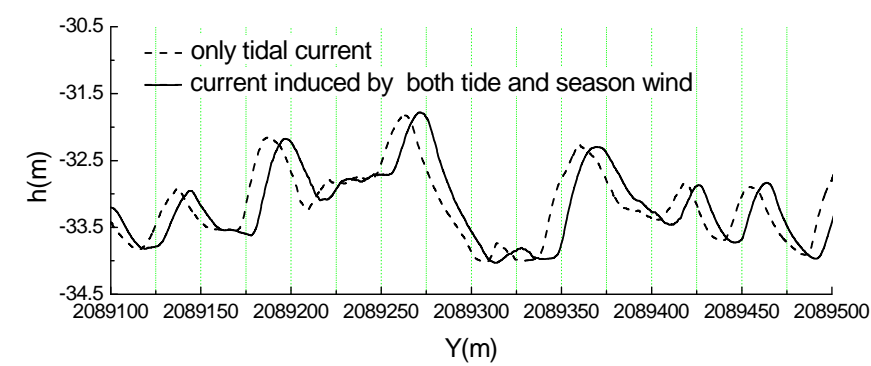

Figure 4. The influence of wind-driven current on sand-wave migration.

From physical knowledge, as the sediment diameter is fixed the shear stress near the bottom determines the sediment transport mode. Now we use two sediment transport formats: one is the bed load + suspended load; another is the bed load alone. Figure 5 plots the crest position using the two formats in different water depths. As the water depth is $34.9 \mathrm{~m}$, the calculation results between two formats differ by $3 \mathrm{~m} / \mathrm{yr}$. As the water depth approaches $31 \mathrm{~m}$, the distance for two formats is $9 \mathrm{~m} / \mathrm{yr}$. That is to say that the influence of the water depth is significant. We also conclude that the aspect of water depth is inverse ratio to migration (see [12]):

$$
c \propto g(1 / H)
$$

In the equation (7), the first term represents sediment launching and the second term represents environmental contribution. C1 and $\mathrm{C} 2$ are constants. By analyzing the calculation results in ridge groove, we have obtained an appropriate relation (see [12]), as shown in Figure 6.

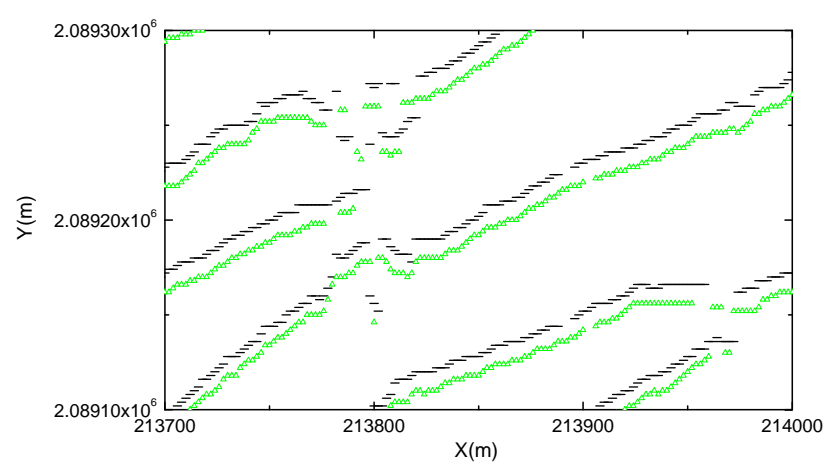

(a) $H_{\text {aver }}=31.3 \mathrm{~m}, \delta=9 \mathrm{~m}$

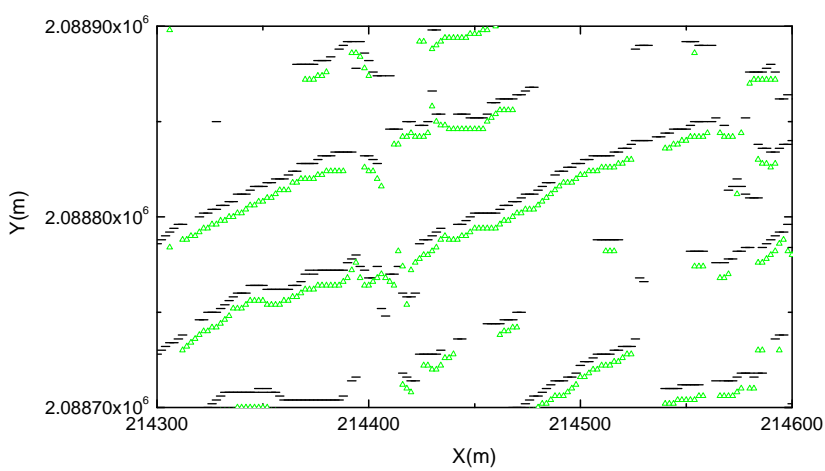

(b) $H_{\text {aver }}=34.9 \mathrm{~m}, \delta=4 \mathrm{~m}$

Figure 5. Comparing the crest of the sand-wave with different sediment transport models. The "-" depicts bed load model and the“ $\Delta$ " depicts bed load and suspended load. $H_{\text {aver }}$ means average water depth in the every small area,

$\delta$ means interval of results by two models.

Now we use this formula (7) to predict the movement of sandwave located on the sand ridge back. According to the sandwave properties obtained by the observed data in July 2004, we can find that the predicted solutions (dash line in Figure 6) are good agreement with observed data in Oct. 2005. It is emphasized here that, although the results are inspiring, the predictions depend on the observed data in the whole study area.

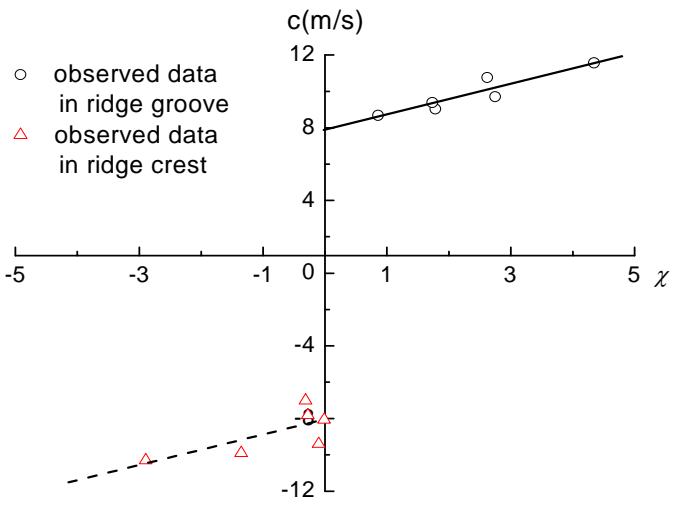

Figure 6. The solid line is fitted results at ridge groove sites. The dash line depicts predicting results for sand-wave in ridge back sites. 
Moreover, it should pay more attention to the sand-wave located on the sand ridge back. From Figure 2, we show that, as the water depth is rather shallow (such as an averaged water depth near $31 \mathrm{~m}$ ), the prediction fails. What causes such failure? From the observed data in the region, we found that the migrating direction of the sand-wave was opposite to the residual current [8]. This phenomenon is also observed by Lanckneus, Besio and Thaiënne ([13], [14], [15] and [16]). Besio demonstrated that the combined function of harmonic constituent M4 and residual current Z0 may cause sand-wave migration in the direction against the residual flow. Thaiënne reckoned that the differences are due to the relative importance of tidal currents and wave activity near the bed. Lin [17] also supports this viewpoint and has developed a physical simulation model to give a qualitative explanation. We think the latter consideration may be felicitous for the study area. Reviewing hydrological data from July 2004 to Oct. 2005, we find that there are three typhoons passing through the area during that time. So the wave activity due to the typhoons could not be neglected.

It is concluded that the physical models presented in this paper should be used to predict the migration of the small scale sandwave, which is rarely dominated by wave activity. We will consider about the mechanism of sand-wave moving direction in the near future.

\section{ACKNOWLEDGMENTS}

The financial support from NSFC (Grant No.40576046) and the project of CAS (KZCX2-YW-212-2) and the "863" programs (No. 2006AA09Z301) are gratefully acknowledged.

\section{REFERENCES}

[1] Whitehouse, R. J. S., Damgaard, J. S., and Langhorne, D. N., 2000, "Sand waves and seabed engineering: application to submarine cables", Marine Sandwave Dynamics, International Workshop, March 23-24, University of Lille 1, France Proceedings, Trentesaux A and Garlan T Ed, pp. 227-234.

[2] Besio, G., Blondeaux, P., Brocchini, M., et al., 2008, “The morphodynamics of tidal sand waves: A model overview", Coastal engineering, Vol. 55, pp. 657-670.

[3] Passchier, S., Kleinhans, M. G., 2005, “Observations of sand waves, megaripples, and hummocks on the Dutch coastal area and their relation to currents and combined flow conditions”, Journal Geophysics Research, Vol. 110 (F04S15, doi:10.1029/2004JF000215).

[4] Hulscher, S. J. M. H., 1996, “Tidal-induced large-scale regular bed form patterns in a three-dimensional shallow water model”, Journal of Geophysical Research, Vol. 101 (C9), pp. 20727-20744.

[5] Gerkema, T., 2000, "A linear stability analysis of tidally generated sand waves”, Journal of Fluid Mechanics, Vol. 417, pp. 303-322.

[6] Komarova, N. L., Hulscher, S. J. M. H., 2000, "Linear instability mechanics for sand wave formation”, Journal of
Fluid mechanics, Vol. 413, pp. 219-246.

[7] Németh, A. A., Hulscher, S. J. M. H. and De Vriend, H. J., 2002, "Modelling sand wave migration in shallow shelf seas”, Continental Shelf Research, Vol. 22, pp. 2795-2806.

[8] Lin, M., Li, Y., 2009, "Observation and Theoretical Analysis for the Sand waves Migration in the North Gulf of South China Sea", Chinese Journal of Geophysics (accepted).

[9] Cookman, J. L., Flemings, P. B., 2001, “STORMSED1.0: hydrodynamics and sediment transport in a 2-D, steadystate, wind and wave-driven coastal circulation model”, Computers Geosciences, Vol. 27, pp. 647-674.

[10] Glenn, S. M., Grant, W. D., 1987, “A suspended sediment stratification correction for combined wave and current flows”, Journal of Geophysical Research, Vol. 92(C8), pp. 8244-8264.

[11] Knaapen, M. A. F., 2005, "Sandwave migration predictor based on shape information”, Journal of Geophysical Research, Vol. 110, F04S11, doi: 10.1029/ 2004 JF 000195.

[12] Li, Y., Lin, M., 2009, "Processes controlling the sand waves migration in the North Gulf of South China Sea", Ocean Engineering (submitted).

[13] Lanckneus, J., De Moor, G.., 1991, "Present-day evolution of sand waves on a sandy shelf bank", Oceanologia Acta, SP-11, pp. 123-127.

[14] Besio, G., Blondeaux, P. and Frisina, P., 2003, “A note on tidally generated sand waves”, Journal Fluid Mechanics, Vol. 485, pp. 171-190.

[15] Besio, G., Blondeaux, P., Brocchini, M. and Vittori, G., 2004, "On the modeling of sand wave migration", Journal of Geophysical Research, Vol. 109(C4), doi:10.1029/2002 JC001622C04018.

[16] Thaiënne, A. G. P. D., Maarten, G. K., 2005, "Processes controlling the dynamics of compound sad waves in the North Sea, Netherlands”, Journal of Geophysical research, Vol. 110, Fo4S10, dio:10.1029/2004JF000173.

[17] Lin, M., Yuan, Z. D., 2006, "Estimating the speed of cross shore sand waves", The 16th International Offshore and Polar Engineering Conference, San Francisco, California, USA, pp. 717-722. 